Religious Studies (2022) 58, 113-137 @ The Author(s), 2020. Published by Cambridge University Press. This is an Open Access article, distributed under the terms of the Creative Commons AttributionNonCommercial-NoDerivatives licence http://creativecommons.org/licenses/by-nc-nd/4.0/, which permits non-commercial re-use, distribution, and reproduction in any medium, provided the original work is unaltered and is properly cited. The written permission of Cambridge University Press must be obtained for commercial re-use or in order to create a derivative work. doi:10.1017/S0034412520000141

\title{
Did natural selection select for true religious beliefs?
}

\author{
HANS VAN EYGHEN (1) \\ Faculty of Religion and Theology, VU Amsterdam, De Boelelaan 1105, $1081 \mathrm{HV}$ \\ Amsterdam, The Netherlands \\ e-mail: hansvaneyghen@gmail.com
}

\section{CHRISTOPHER T. BENNETT}

Faculty of Theology and Religion, Oxford University, Gibson Building, Radcliffe Observatory Quarter, Woodstock Road, Oxford OX2 6GG, UK

e-mail: christopher.bennett@theology.ox.ac.uk

\begin{abstract}
Although it is commonly accepted that Darwinian evolution could select for true common-sense beliefs, it is altogether less certain that the same can be said for other classes of beliefs, such as moral or religious beliefs. This issue takes centre stage in debates concerning evolutionary debunking arguments against religious beliefs, where the rationality of beliefs is often dependent upon their production by an evolved faculty that is sensitive to truth. In this article, we consider whether evolution selected for true religious beliefs. We begin by highlighting the relevance of this question for broader philosophy of religion, then present a dialogue of arguments and counter-arguments for and against the proposition that true religious beliefs generate pragmatic success and hence can be selected for by evolution.
\end{abstract}

\section{Introduction}

Since Charles Darwin, ${ }^{1}$ people have wondered if and how natural selection could select for true beliefs. The debate has been rekindled by Alvin Plantinga's famous evolutionary argument against naturalism, and evolutionary debunking arguments from various philosophers against moral and religious realism. ${ }^{2}$ In this article, we will focus on a subsection of the debate: whether natural selection can be expected to have selected for true religious beliefs. The article contains arguments for (Hans Van Eyghen) and against (Christopher T. Bennett) the central thesis. 
With the emergence of Cognitive Science of Religion (CSR), much discussion has arisen over the question whether religious belief is epistemically tainted by its evolutionary past. The main CSR theories claim that a propensity for religious belief would have evolved regardless of its truth. In this article we examine more closely arguments for and against the pragmatic, evolutionary value of true religious beliefs, a relevant consideration for discerning their epistemic status in light of CSR.

Any given belief must fulfil certain conditions for its accurate production to be linked with pragmatic success. Thus, on the whole, one ought not to expect that just because a faculty enhances fitness, the beliefs it produces are likely to be true. Of course, such beliefs are not necessarily likelier to be false, but the pragmatic success of certain human enterprises alone cannot be used as justification of their ultimate truth. We will begin by stating definitions; then we will discuss how some authors argue that evolutionary explanations undermine the justification of beliefs; third, we will discuss a response stating that truth and evolutionary success can be linked; fourth, one of us (Hans Van Eyghen) argues that evolutionary success and truth of religious belief can be linked; fifth, the other (Christopher T. Bennett) argues that they cannot be linked; the last two sections contain rebuttals.

But first, some definitions of key terms:

'Belief-forming faculties (BFFs)' will here describe some mental or physical ability that leads to the holding of beliefs. In cognitive science, such faculties are often called 'cognitive mechanisms'.

'Pragmatic success' differs in precise meaning with the field to which it is applied, but will be understood evolutionarily in this article, as a property that a faculty or belief might possess which increases the fitness of the organism $^{3}$ that possesses it.

'tracking truth', or 'truth-tracking' will be used interchangeably with the term 'reliable' to describe a faculty that at least most of the time produces beliefs that are objectively true.

'objective truth' is taken to mean that which is in fact true of the world, independent of whether humans think it to be true.

These definitions are all based on the common-sense usage of the terms within the context of this dispute and are not attempts to alter the parameters of success in this debate. We believe them to be reasonable in setting out a useful area of inquiry.

Before embarking on the main topic, it is useful to enumerate human pursuits in which truth is relevant. The key ones, given the context of this article, are scientific, religious and inferential beliefs. Other possibly affected pursuits include logical deduction, mathematical deduction, art and morality. This extensive list covers broad areas of human culture and understanding. The importance of, and 
methods for seeking, truth in each field varies tremendously, and there is insufficient space to cover them adequately here. Nonetheless, the fundamental thesis behind our discussion is, and ought to be, applicable to any human attempt to discover objective truths.

Consideration of this matter so far has often been implicit and unspoken. Until recently, the debate was not framed in an evolutionary or psychological way, but addressed epistemological possibilities more broadly. The talk of 'faculties' in which this article will primarily be engaged is indicative of an anthropocentric approach that is unconcerned whether a hypothetical being could know metaphysical facts, but concentrates on whether an evolved human is able to know objective truths. Hence, this debate fits a historical context but also sits apart from it, meaning different arguments will be utilised in response to the typical epistemological challenges.

\section{Evolutionary debunking arguments}

The issue of justification by pragmatic value is raised in discussions of debunking arguments against common-sense, religious and moral beliefs. John Wilkins and Paul Griffiths (2013) introduce the idea to save common-sense beliefs from evolutionary scepticism. Important assumptions they make are that humans can know only what their evolved BFFs tell them, and that the Darwinian theory of evolution holds. In this section, we discuss what evolutionary debunking is and how pragmatic value saves beliefs from evolutionary debunking.

Wilkins and Griffiths (W\&G) note that evolution feeds scepticism to three classes of beliefs. Several evolutionary debunking arguments have been proposed against moral beliefs, ${ }^{4}$ others against religious beliefs, and still others against commonsense and scientific beliefs. ${ }^{5}$ The general structure of evolutionary debunking arguments is well captured by Guy Kahane:

Causal premise. S's belief that $\mathrm{p}$ is explained by $\mathrm{X}$

Epistemic premise. $\mathrm{X}$ is an off-track process

Therefore, S's belief that $\mathrm{p}$ is unjustified. (Kahane (2011), 106)

Two terms in the general structure stand in need of clarification, ' $\mathrm{X}$ ' and 'off-track'. The ' $X$ ' in the general structure is natural selection. Both Kahane and W\&G argue natural selection explains why subjects hold certain beliefs. We argue for an expanded claim, that beliefs are explained by a belief-forming faculty (BFF) that is shaped by natural selection. Referring to BFFs is helpful for two reasons. First, some have argued that natural selection does not directly select for beliefs. Beliefs are mental states and it is hard to see how natural selection can select for them. It makes more sense if natural selection selects for certain capacities to form beliefs. Second, referring to BFFs does more justice to the active role of the human mind in how beliefs are formed. What beliefs a subject has is best 
explained by how the human mind processes inputs and how it uses various cognitive mechanisms to generate beliefs.

The second term that needs clarification is 'off-track'. W\&G take an off-track process to be 'one that does not track truth' or '[one that] produces beliefs in a manner that is insensitive to the truth of those beliefs' (Wilkins \& Griffiths (2013), 134, emphasis added). An off-track process is inadequately attuned to its purported goal. For example, an off-track thermometer is insensitive to heat and cold. W\&G suggest that the goal of BFFs is forming true beliefs (or at least approximately true beliefs). A BFF is therefore off-track if it is not adequately tuned to objective truth. A clear example of a BFF that is off-track is the self-serving bias. Research suggests people are prone to take credit for personal success and blame external factors, or others, for failure. ${ }^{6}$ People thus have a BFF that produces belief that they themselves are responsible for personal success and external factors are responsible for personal failure. It will do so whether people are actually responsible for personal success or not. While it can lead people to hold true beliefs - sometimes people deserve praise for personal success - it will often lead to false beliefs.

Proponents of evolutionary debunking claim that evidence showing a BFF was selected for by natural selection is evidence that the BFF is off-track. ${ }^{7}$ Natural selection selects for fitness-enhancing traits. It will therefore select for BFFs that increase an organism's chances of reproduction. Whether the BFF produces true beliefs is of no concern to natural selection. Natural selection could just as easily select for off-track BFFs as for on-track BFFs, depending which yielded greater adaptive value.

W\&G note that BFFs that produce common-sense beliefs, moral beliefs, and religious beliefs were shaped by natural selection. Our main concern lies with religious beliefs. Most research on BFFs that produce religious belief comes from CSR. Most theories in CSR agree that religious BFFs were shaped by natural selection, at least implicitly.

Two camps can be distinguished in CSR. The first claims that religious beliefs have adaptive value in themselves. According to one influential theory, belief in moralizing, punitive gods aids human cooperation. Humans who believe that there is a supernatural being watching their every move are more likely to contribute and less likely to free-ride. If they believe humans will be punished or rewarded in accordance with their moral behaviour, they have an even stronger incentive to cooperate to the fullest of their abilities. Because cooperation is very important for human survival, better cooperation leads to a greater likelihood of survival. ${ }^{8}$ On this theory, BFFs for religious belief would have been selected because being religious aids cooperation.

The second camp claims religious beliefs themselves have no adaptive value but arose as by-products of other adaptive traits. Just as spandrels automatically arise when large buildings are built, by-products automatically arise with adaptive traits. ${ }^{9}$ Usually proponents of by-product theories argue that some adaptive BFF 
is 'overly active', when forming religious beliefs. An example is mentalizing. Mentalizing produces beliefs about others' mental states. On one prominent theory, people form such beliefs by attending to other people's behaviours and facial expressions. When someone makes abrupt movements and has a frowny face, people usually believe that person is angry. Having an on-track mentalizing BFF is adaptive. To cooperate and pre-empt attacks from others, it is useful to estimate their thoughts and feelings accurately. According to one CSR-theory, religious beliefs are a by-product of mentalizing. Because mentalizing is prevalent, people apply it to other phenomena. Meaningful events in particular trigger mentalizing. When humans experience events like a beautiful sunset or the birth of a child, the significance makes them prone to seeing the event as an expression of a mind. In other words, people believe someone is trying to communicate through the event. Thus, humans often infer actions of a divine mind, ${ }^{10}$ though forming beliefs about a divine mind is not itself adaptive. Our general capacity for mentalizing was selected and the religious beliefs were a non-adaptive consequence of that. ${ }^{11}$

Both camps suggest that natural selection caused religious BFFs, either because they served an adaptive function themselves, or as a by-product of another adaptive function. None of the accounts we discussed maintains that religious beliefs evolved because they are true, so BFFs for religious beliefs would have been selected for whether they produce true beliefs or not. If the beliefs they produce are false, they still yield adaptive benefit or could still evolve as a by-product. Truth thus makes no difference for the evolution of BFFs for religious beliefs. Therefore, according to $W \& G$, religious BFFs are off-track, making their justification questionable. W\&G acknowledge that other BFFs were also selected by natural selection. To save common-sense beliefs, they argue that true common-sense beliefs can be linked to evolutionary success. We turn to this argument in the next section.

\section{Natural selection, pragmatic success, and truth}

To defend common-sense beliefs, $W \& G$ argue that it is more evolutionarily advantageous to have (approximately) true than false common-sense beliefs. This is the core idea behind what they call a 'Milvian Bridge'. ${ }^{12}$ A BFF 'crosses the/has a Milvian Bridge' if there is a link between its pragmatic success and its truth-tracking. W\&G propose an argument for a Milvian bridge for common-sense beliefs and against one for religious beliefs.

W\&G's discussion of common-sense beliefs shows that they mostly have beliefs about the physical world in mind. ${ }^{13}$ These beliefs are typically formed by means of perceptual BFFs. Perceptual BFFs process sensory input and produce beliefs about the world we inhabit. Having perceptual BFFs that produce true beliefs about the physical environment is more evolutionary advantageous than BFFs that produce false beliefs, so increased evolutionary success and truth can be linked by a 'Milvian Bridge'. W\&G define this as: 
Milvian Bridge: $\mathrm{X}$ facts are related to the evolutionary success of $\mathrm{X}$ beliefs in such a way that it is reasonable to accept and act on $\mathrm{X}$ beliefs produced by our evolved cognitive faculties. (Wilkins \& Griffiths (2013), 134)

By introducing the Milvian Bridge, $W \& G$ argue that beliefs' truth and fitness are not mutually exclusive. Although evolutionary pressures will lead to false beliefs on many occasions, ${ }^{14}$ having true common-sense beliefs is often more evolutionary beneficial than having false beliefs. Having mostly false beliefs about the physical environment would lead to great costs. For example, people who have false beliefs about their physical environment will frequently collide with objects and lose their way often. This greatly impedes chances of survival. Therefore, natural selection is more likely to select for BFFs that make humans form true beliefs about their physical environment.

W\&G argue that in order to be regarded as on-track, BFFs should yield an evolutionary benefit because they produce true beliefs. If BFFs generated false beliefs about the physical environment, they would yield not evolutionary benefit but evolutionary disadvantage. In this light, $W \& G$ appear to support this claim as an epistemic criterion:

A BFF is on-track if it yields an evolutionary benefit by virtue of its producing true beliefs.

W\&G allow other ways in which a BFF can be shown to be on-track. Most of the BFFs that produce scientific beliefs (e.g. finding statistically meaningful correlations, calculating derivatives) did not yield evolutionary benefits for most of human history. W\&G argue that BFFs like these can be regarded as reliable because they indirectly depend on reliable BFFs. Just as natural selection probably selected for reliable perceptual faculties, it probably selected for reliable reasoning faculties. It is much more adaptive to be able to make correct inferences, deductions, and generalizations than not. Being able to have true beliefs by reasoning was evolutionarily beneficial, as our ancestors could utilize better strategies for hunting or finding food, and so on. These reliable reasoning faculties can in turn support scientific endeavours that were not directly selected for by natural selection.

Some authors argue that the reliability of reasoning faculties can indirectly support religious beliefs. ${ }^{15}$ Religious belief can itself be supported by reasons. Examples are arguments from natural theology, such as the cosmological or ontological argument. If reasoning has proved reliable because it yielded evolutionary beneficial true beliefs, there is no reason why it should not be reliable when applied to reasoning in arguments like these. W\&G also leave this possibility open. They note that religious beliefs could be supported by arguments from natural theology (Wilkins and Griffiths (2013), 12). Thus W\&G's argument, if sound, does not harm all religious beliefs. Religious beliefs that are formed by means of reasoning can still be justified or rational even if evolved BFFs for religious beliefs are unreliable. 
W\&G suggest that natural selection need not select for beliefs that produce true beliefs. Although having true beliefs about the physical environment would be more evolutionarily beneficial than having false beliefs, W\&G add that their argument is better considered as an argument for evolutionary success of approximately true beliefs. They note that advancements in science taught us that many of our common-sense concepts are mistaken. For example, physics taught us that a solid table is in fact an area of mostly empty space - a naïve commonsense belief like 'there is a solid table in front of me' is thus false. Nonetheless, science does not give grounds to doubt all our common-sense beliefs; we can still justifiably possess a conceptual scheme that is not completely arbitrary and is constrained by reality. W\&G move from an argument for pragmatic success of true beliefs to an argument for pragmatic success of certain beliefs that are nonarbitrary and constrained by reality.

What 'non-arbitrary' and 'being constrained by reality' mean is subject to discussion. The terms bear a resemblance to 'truth approximation'. Truth approximation is often regarded as a measure of how much a belief resembles the actual state of affairs or objective truth. ${ }^{16}$ For example, a belief that there is a solid table appears to resemble the actual state of affairs better than a belief that there is a blurry mass. The epistemic criterion stemming from the Milvian Bridge should therefore be restated as:

A BFF is on-track if, and only if, it yields an evolutionary benefit by virtue of its producing approximately true beliefs.

Rephrasing W\&G's argument in terms of truth approximation raises questions. A belief should approximate truth to a sufficient extent to reduce evolutionary costs. It is not clear what sufficient truth approximation is. Some beliefs may be underdetermined by the input of the actual state of affairs, because natural selection selects for behaviour rather than beliefs. In his evolutionary argument against naturalism, Plantinga $(1993 ; 2011)$ suggests that multiple beliefs can make a subject respond appropriately to a predator. Someone with the true belief that the predator poses a real threat will have the evolutionarily successful reaction of fleeing. Someone with the false beliefs that the predator is cute and that the best means to pet the predator is running away, will also survive. Applied to our table example, it seems that someone who believes that there is a solid table will have very similar behaviour to someone who believes that there is a smooth rock. Settling thresholds for truth approximation and choosing among equally successful beliefs lie beyond the scope of this article.

In summary, W\&G argue that having approximately true beliefs about the physical environment leads to greater evolutionary success. Although they draw a strong link between pragmatic success and truth of common-sense beliefs, they deny that a similar case can be made for moral or religious beliefs, which thus fail to cross the Milvian Bridge and are debunked. In the next section, Hans Van Eyghen argues that a similar case can be made for religious beliefs. 


\section{The case for pragmatic value of true religious beliefs}

We noted in the previous section that W\&G deny that the truth of religious beliefs is correlated with their pragmatic success. They claim that leading accounts of the evolution of religious belief make no reference to the truth of religious beliefs to explain their adaptive value. The accounts do allow some pragmatic, evolutionary success for religious beliefs, but this is not due to their truth. In this section, I provide a plausible argument for pragmatic value of religious beliefs, positing that true religious beliefs can contribute to human flourishing by leading to a life of higher sanctity.

W\&G's Milvian Bridge draws on the need to cope with the physical environment. To survive, humans must navigate the physical environment. While approximately true physical beliefs aid in doing so, approximately true religious beliefs do not. However, approximately true religious belief aids in coping with another environment, the spiritual environment. This claim draws on William Alston's (1991) defence of mystical experiences. Alston suggests that providing a subject with a 'map' of the spiritual environment is the basic aim or function of mystical experiences. Testing whether the 'map' is accurate, therefore, means testing whether mystical experiences allow subjects to navigate the spiritual environment successfully. Success is achieved if mystical experiences provide guidance to interact successfully with God. To make his case, Alston compares mystical experiences to another belief-forming practice that does not produce beliefs about the physical environment: interpersonal perception - our awareness of other persons. Forming interpersonal beliefs is much less straightforward than forming perceptual beliefs. They are also harder to test. Nonetheless, the practice, and its outputs, can be tested by assessing how well they permit successful interactions between persons.

Religious beliefs can help subjects cope with the spiritual environment by helping them successfully interact with God (or other supernatural beings). If there is a spiritual environment, subjects with approximately true religious beliefs will be better able to interact successfully with God. ${ }^{17}$ I argue that the only situation where this does not hold is a situation where there is no spiritual realm.

If there is a spiritual realm, BFFs can produce approximately true religious beliefs or false religious beliefs. If they produce false beliefs, for example if they produce a belief about God that is vastly different from how God actually is or if they produce the belief that God does not exist, subjects are not able to interact successfully with God. If they have approximately true beliefs, they are far more likely to be able to do so.

If there is no spiritual realm, having approximately true or false beliefs makes no difference. If BFFs produce true beliefs, i.e. that there are no supernatural beings, the beliefs are irrelevant because there is no object for interaction. If they produce the false belief that God exists, subjects might think that they are engaging with 
God, when in fact they are not. Therefore, in both cases, subjects' true or false religious beliefs make no difference.

I have thus far argued that having BFFs for religious beliefs that are on-track only makes no difference if there is no spiritual realm. This does not suffice to establish a Milvian Bridge. Having approximately true beliefs and the successful interaction they yield must also bring evolutionary benefit. I argue that having approximately true religious beliefs can have this benefit by leading to a life of greater flourishing, by leading to a life of greater sanctity.

Alston argues at length that mystical experiences can lead to a life of greater sanctity. Alston is reluctant to define what sanctity is but gives this description:

\begin{abstract}
It [sanctity] involves a radical turning (conversion) of oneself from preoccupation with the satisfaction of desires for sensory gratification, creature comforts, keeping up with the latest trendy consumer goods, one's own peace and serenity, one's status and reputation, and other self-centered aims; it involves turning away from this in the direction of an aim at loving communion with God and with one's fellows. It involves letting go of one's insistence on controlling one's destiny and opening up oneself to the Spirit, receiving the fruits of the Spirit love, joy, peace, and so on - as free gifts ... It involves living one's life in the presence of God, following whatever vocation is given one by God. It involves opening oneself up to other people and loving them... as God does. (Alston (1991), 251)
\end{abstract}

Alston is firm that self-support for mystical experiences does not justify individual religious beliefs, like the Christian Trinitarian belief. However, if mystical experiences gain self-support, some religious beliefs that they yield will be supported too. The beliefs that are supported will be those which constitute the map by means of which a person interacts with God. Just as a person usually does not rely on detailed beliefs about the kind of wood that constitutes a solid table to use the table for eating, most religious believers will not need detailed beliefs about the nature of God to successfully interact with Him. Other beliefs, such as the belief that God is loving or the belief that God is forgiving, will be more important.

Alston's link between interacting successfully with God and sanctity indicates how pragmatic spiritual success can result in evolutionary success. Apart from minor benefits that come with sanctity, such as reduced stress or better health, ${ }^{18}$ sanctity shows that putative interactions with God can change how a person behaves and lives her life. If there is a God who has a plan for humans, it is likely that He will direct humans on that path. If that God is good, He will lead humans on a path that is beneficial. Following that path will then lead to human flourishing.

As is the case for most species, flourishing probably benefits human survival. Organisms that flourish tend to have greater longevity, which gives them more chances of producing and protecting offspring. For humans, flourishing also leads to more positive emotions and increased life-quality. Lack of flourishing puts stress on human relationships, which are highly important for human survival and procreation. ${ }^{19}$ 
The debunker can still drive a wedge between the pragmatic success of sense perception and that of supernatural belief. She can claim that the pragmatic success of sense perception is much greater. Sense perception allows scientific beliefs. Their pragmatic success is more impressive than that of supernatural beliefs. The success of scientific beliefs ranges from rockets to cures for diseases. Its impacts make it very unlikely that beliefs resulting from sense perception are not aimed at truth. By comparison the success of supernatural belief appears meagre.

Alston (1991) pre-empted this objection. He notes that mystical experiences (and the beliefs they yield) do not allow for predictions while perceptual beliefs do. Perceptual beliefs also allow for intersubjective testing while mystical experience does not, because its object is harder to grasp. He responds that we should not expect the same success, because we cannot expect God to be perceivable at every moment. The object of mystical experience, i.e. God, should not be treated in the same way as the object of perceptual beliefs. We use different tests for introspection from those we use for sense perception. Introspection does not allow for predictions and intersubjective checking either.

Debunkers can also reply as follows: one or a combination of the evolutionary explanations of religious belief (see above) can explain why people developed a BFF for religious belief without referring to spiritual growth or to the truth of religious beliefs. Religious beliefs can have a pragmatic use that leads to greater evolutionary success, but the truth of religious beliefs is not needed to explain why BFFs for religious belief evolved. To avoid W\&G's debunking argument, any explanation, or the most plausible explanation, for why we have religious BFFs must include reference to the truths they produce.

Against this reply, I argue that no evolutionary explanation fully explains a BFF. As Robert McCauley (2007) notes, explanations are by their very nature reductive. They focus on one or a few aspects of a phenomenon and explain why or how they came to be that way. By doing so, they necessarily leave out other aspects of the explanandum. Some explanations have a broader scope than others. Some explanations of perceptual BFFs with a small scope also do not refer to truth. For example, some explanations of 'event cognition', cognition that involves chunking up experiences, argue that humans tend to separate two events when features of the observed situation change drastically. ${ }^{20}$ Doing so helps human recollection. The explanation of why humans carve situations into separate events thus does not refer to truth; humans do not use event cognition because there are actual, separate events out there. The explanations claim that humans primarily create events to aid memory.

Claiming that human cognition is insensitive to truth based on the explanation of event cognition is unwarranted. Event cognition merely suggests that carving situations up in events is not always sensitive to truth. Other aspects of cognition fall beyond the explanation's scope. Because these other aspects may be constrained by truth, no strong conclusions about human cognition can be drawn. 
For religious BFFs, evolutionary explanations are also limited. Adaptationist explanations explain why people tend to believe in moralizing gods and byproduct explanations explain why people developed the ability to form religious beliefs. Neither explains specifically why people form specific beliefs about God (or other supernatural beings) with whom they can engage and who they believe gives guidance to their lives. Engaging with God is not explained by evolutionary explanations and can more plausibly be explained by the pragmatic value it yields. In this sense, referring to the pragmatic value of sanctity gained by religious beliefs adds additional information which other evolutionary explanations lack.

To argue that BFFs for religious belief are unconstrained by reality, one must argue that the (evolutionary) explanations, which do not refer to the truth of religious beliefs, are of sufficiently broad scope to explain the religious beliefs people have. I argued that they are not.

\section{The case against pragmatic success of religious beliefs}

In the previous section, Van Eyghen defended the reliability of religious BFFs understood within Wilkins and Griffiths' framework. Working within that same framework, I, Christopher T. Bennett will counter his argument. I will elucidate the disconnect between religion as a BFF that increases fitness and religion as a BFF that seeks objective truth. As a preliminary consideration, I observe that there are many religious beliefs that are based in the world. The beliefs 'Jesus died on the cross' and 'Muhammad captured Mecca' are historical, religious beliefs. In terms of how they are produced, they do not require 'religious' BFFs, because they are ultimately natural facts, so they are not kinds of beliefs with which we are concerned. What we are more interested in is supernatural beliefs, such as 'Jesus was the Son of God' or 'Allah spoke to Muhammad'. Can one make the necessary connection between the BFFs that produce such beliefs and pragmatic success?

Before answering that question, I shall briefly revisit W\&G's evolutionary debunking argument (EDA), to embellish the importance of pragmatic success. According to the Milvian Bridge principle, it would have to be the case that religious BFFs improve fitness because of their truth for them to be known to be reliable. Although an EDA based on the Milvian Bridge principle would have potential vulnerabilities concerning self-referential coherence and an inability to remove justification from all religious beliefs, these are surmountable problems. ${ }^{21}$ If one agrees with the basic acceptability and possible impact of the Milvian Bridge, then it becomes imperative to investigate the pragmatic success of religious beliefs.

From the evidence of CSR, religion's prevalence and spread are based on factors external to the truth of religious beliefs. The very nature of BFFs that generate metaphysical beliefs means that passing the test imposed by the Milvian Bridge principle is prima facie unlikely. To claim that the physical environment propagates reliable religious BFFs is implausible; such faculties aim at a fundamentally 
different subject matter from common-sense faculties. The purpose of empirical faculties is to provide information about the world around us. This is the same for inferential and mathematical faculties - their aims are to represent something that is real about the physical world (in these two cases, causal or numerical connections). Religious BFFs are also aiming at an objective truth, but they seek to represent the metaphysical world.

The critical difference between common-sense and religious BFFs, explaining why the former cross the Milvian Bridge blatantly but not the latter, is that the physical world is what is causally efficacious in the evolution of BFFs. As the ultimate measure of whether a BFF is beneficial is physical, metaphysical truths do not have the same causal influence on metaphysical faculties as physical truths can have on physical faculties. Put simply, not being able to see that you are worshipping the wrong god is not going to affect you until the devil gets you in the afterlife, after you have reproduced and spread your blasphemy. However, not being able to see a lion speeding towards you is going to affect your ability to reproduce drastically and immediately. ${ }^{22}$ Given the nature of the world in which human BFFs evolved, crossing the Milvian Bridge is not a simple prospect for religious beliefs. Given that the Milvian Bridge principle has at least some merit, and that religious BFFs seem, at least initially, to fail its test, an EDA based upon it threatens the justification of religious beliefs. Thus, it is imprudent simply to deny the need for a link between pragmatic success of religious beliefs and reliability. If any weight is given to $\mathrm{W} \& G^{\prime}$ s compelling EDA against religion, a connection between pragmatic success and religious beliefs must be found. For this reason, it is valuable that Van Eyghen offers reasons to believe that religious BFFs can be known to be reliable because their truth-seeking is adaptive. I will argue, contrary to this position, that pragmatic success is not linked to religious truths. Such a conclusion would entail that religious BFFs cannot be known, on the basis of the Milvian Bridge principle, to be reliable, and so beliefs based upon them stand in danger of being debunked, all else being equal.

\section{Addressing Van Eyghen's attempt to find a link}

Both Van Eyghen and I see the potential threat posed by debunking arguments, particularly those of the style aiming at religious faculties. We also agree that the Milvian Bridge principle discerns the reliability of BFFs. Hence, it is imperative that pragmatic success be linked to the benefit that religious faculties provide. There is also consensus between us that behaviours such as religion and morality are ostensibly based on metaphysical truths but have evolutionary effects. Van Eyghen asserts their reliability, arguing the precise opposite of me, 'that religious beliefs can make a claim to pragmatic success'. His argument is based on William Alston's (1991) epistemology, which asserted the basicness of religious beliefs and the advantages of having them. There are two key claims: (1) 'religious beliefs can lead to a life of greater spiritual fulfilment' and (2) 
'spiritual fulfilment can be evolutionary beneficial'. Depending on the definition of the term 'spiritual fulfilment', I actually agree with both claims, but don't believe they do enough to confirm Van Eyghen's key claim.

Alston and Van Eyghen draw a parallel between empirical and religious BFFs. Empirical faculties try to provide an accurate picture of the world; spiritual faculties try to present an accurate picture of the spiritual world. The argument then is that just as an accurate picture of the physical world is useful for an organism to navigate, so an accurate picture of the spiritual world can be useful, because it promotes human flourishing. I agree with assertions 1 and 2 that Van Eyghen makes because I define spiritual fulfilment as something that a human feels when he or she is content with his or her spiritual beliefs. This is a worldly, physical emotion that can be felt by humans of all creeds and may be evolved behaviour. Van Eyghen's definition of spiritual fulfilment is more akin to 'an accurate picture of the spiritual landscape', i.e. objective truths about the religious reality. Ultimately, I believe it is sleight of hand that mixes up these two definitions and makes his position look more convincing than it in fact is.

The parallel between spiritual and empirical faculties has appropriate intentions, because if successful it would allow for a link between religious beliefs and pragmatic success. Nonetheless, any comparison breaks down due to its faulty equivocation of two fundamentally different BFFs. Even if one considers each of them to build up accurate pictures of worlds, the two worlds have notably different causal impacts. I remarked earlier that one might never know if one were living by metaphysically wrong principles, due to their lack of influence on physical occurrences. Common-sense BFFs, on the other hand, produce varying levels of fitness depending on their correspondence to physical reality, because of the material consequences of having inaccurate beliefs. It is implausible to give a realistic example of pragmatic failure arising due to unreliable metaphysical BFFs.

One such possible story might include a God who ensures those with correct religious beliefs reproduce plentifully, whereas those who are metaphysically wrong are unfit and smitten. Indeed, the Milvian Bridge instance that W\&G provide, while being historically questionable, would, if the legend is true, be an appropriate example. ${ }^{23}$ The God-fearing emperor who is metaphysically correct conquers the wrong-headed pagans thanks to God's will and therefore allows the spread of other correct people. One can plainly see how religious truthfinding correlates with adaptive fitness. But the important point is that to use this as an example for his argument, Van Eyghen would have to know beforehand that Emperor Constantine was right, not the pagans, and that the reason for victory was his rightness. The latter claim seems impossible to substantiate without the former, and the former claim makes an assumption about religious correctness, totally pre-empting this entire discussion. As a further consideration for this style of argument, very few theists would endorse such a framework even if the 
other problems were resolved, as this would probably invoke difficult theological questions of free will, occasionalism, and the problem of evil.

That problematic route, to Van Eyghen's credit, is not the avenue down which he travels. Instead, he argues that spiritual fulfilment (correct religious inclination) leads to human flourishing. Human flourishing brings evolutionary benefit. It may be true that for humans to flourish they need to find spiritual contentment, although this is an empirical claim that would require rigorous testing. But this is not Van Eyghen's contention. Instead he argues that a human holding correct religious beliefs is fitter than one with incorrect religious beliefs. In part this is also an empirical claim: if one could demarcate all the spiritually fulfilled, correct individuals one could then see if they are, on average, more 'fit' than their counterparts. The problem, I suggest, comes with any attempt to discover who these lucky few might be, and so how to discern the causal importance of metaphysical correctness.

In order to discern whether metaphysical rightness leads to evolutionary fitness, or, in Van Eyghen's terms, if spiritual fulfilment of the kind that clearly benefits a human is caused by spiritual righteousness, we have to know what the metaphysical state of affairs is. If those who are right fare better than those who are wrong, it is necessary to know who is right and wrong in the first place, so that one can compare how the groups fare. Otherwise, one is simply guessing that a person whose religion helps them flourish is also metaphysically correct. This can lead to bizarre results: who is to say that Scientology is not the true religion? What about worship of the Greek gods? Each of these sets of beliefs and practices has helped humans to flourish and yet I suspect most defenders of the link between pragmatic success and religious belief would like to deny the truth of them. Accepting that all spiritual fulfilment denotes reliable religious BFFs leads to a vague, relativist position where many religions are uncritically accepted as true.

Given the contradictory nature of different religious doctrines, it seems that any attempt to state that one religion is the metaphysically correct one would be very problematic. There is not much physical difference in the human flourishing that humans of different religions undergo. Buddhists flourish, Hindus flourish, Christians flourish, despite believing fundamentally different things about the spiritual landscape and acting in drastically different ways in relation to it. Hence, using Van Eyghen's criterion for religious truth, we are forced to accept that all religions that enable flourishing are true. Most of these religions have contradictory beliefs so we are led into a contradiction if we agree that spiritual fulfilment is the way to judge whether a religious BFF is truth-tracking. It is impossible to escape the truism that metaphysical faculties do not have the causal influence on evolutionary fitness of perceptual and inferential faculties. ${ }^{24}$

Van Eyghen's equivocation when using the term 'spiritual fulfilment' makes the argument seem prima facie reasonable. Still, by using spiritual fulfilment to mean metaphysical correctness, Van Eyghen turns what would be a reasonable claim if spiritual fulfilment were a physical phenomenon-'spiritual fulfilment aids 
flourishing' - into a contentious one. Spiritual and religious practices make humans feel fulfilled, but we can only judge that from a physical perspective, we cannot claim such practices reveal metaphysical correctness too. The sleight of hand concerning the two different interpretations can make Van Eyghen's argument seem initially convincing. However, to propound the link as he does, one would need to know beforehand the metaphysical state of affairs. As this presumes knowledge that we do not have, his argument begs the question and is unconvincing, reaching contradictions however one understands the term 'spiritual fulfilment'.

Aside from this fundamental problem, I fear that, even if Van Eyghen's argument worked, it would be susceptible to a slippery slope. Van Eyghen's view risks inviting debunking arguments such as Robert Nola's (2013; 2018) and Matthew Braddock's (2016) back into play, as they provide powerful arguments for one not to rely upon CSR mechanisms as sufficient reason for religious justification. By attempting to link religious truth-finding and pragmatic success in the way that he does, Van Eyghen, even if initially successful, risks escaping a fire only to find himself in a frying pan.

\section{Coarse-grained religious beliefs}

In this section, I respond to the claims made in the previous section. I take Bennett to argue that metaphysical BFFs cannot make a claim to pragmatic success. I argue that Bennett is both right and wrong. I agree that fine-grained metaphysical beliefs -such as 'Jesus was the Son of God or 'Allah spoke to Muhammad' - (usually) cannot make a claim to pragmatic success. More coarse-grained metaphysical beliefs - such as beliefs that a loving ultimate being exists or that God is morally concerned - can.

Bennett agrees that there is a Milvian Bridge between perceptual faculties and truth. Because having (approximately) true perceptual beliefs is more evolutionarily beneficial than having false perceptual beliefs, natural selection selects for reliable perceptual faculties. Bennett argues that there are also Milvian Bridges between (some) inferential BFFs and truth. Making many false inferences would greatly hamper human survival.

Bennett firmly states that all metaphysical BFFs do not have a Milvian Bridge. Although metaphysical faculties aim at representing an objective reality (i.e. some moral truth or some religious entity), as do perceptual faculties, this (metaphysical) reality does 'not have the same causal influence on metaphysical faculties as physical truths can have on physical faculties'. Being able to form correct metaphysical beliefs does not affect adaptive success.

Above I argued that religious beliefs can have an indirect causal influence on adaptive success. Before I refine my claim to respond to Bennett's objections, I make a detour to moral beliefs. In response to debunking arguments against moral beliefs, ${ }^{25}$ several authors argue for third factor responses. In W\&G's 
terms, third factor responses can be labelled Milvian Bridges. ${ }^{26}$ David Enoch (2010) argues that having true moral beliefs can be linked to evolutionary success by survival. Beliefs that lead to better odds of survival are undeniably advantageous. Enoch argues that survival can be considered as a moral good. Therefore, beliefs that promulgate survival are morally good. In this way, having (some) true moral beliefs can be selected for by natural selection because the aim of natural selection is morally good itself.

According to Enoch, survival is the Milvian Bridge linking moral truth to evolutionary success. His claim shows that metaphysical realities need not have the same causal influence on metaphysical beliefs that physical realities have on physical beliefs. Subjects indeed do not bump into moral truths like 'killing is wrong' in the same way as they bump into physical realities like 'walls are impenetrable'. However, because moral truths have an evolutionary link to survival, the reality that killing is wrong can exert an indirect causal influence. Because having the belief leads to better odds of survival, subjects with the belief will outcompete subjects without the belief.

The link between moral truths and evolutionary success is far less direct than the link between physical truth and evolutionary success. Therefore positing 'survival' as a Milvian Bridge does not allow for the justification of fine-grained moral beliefs. An example of a fine-grained moral belief is Immanuel Kant's second formulation of the categorical imperative. It states:

Act in such a way that you treat humanity, whether in your own person or in the person of any other, never merely as a means to an end, but always at the same time as an end. (Kant (1993), 429)

While Kant's maxim resembles the maxim that killing is wrong, it is far more elaborate. Holding Kant's maxim as true will lead to less killing and therefore to better odds of survival. It is, however, unlikely that natural selection will select for faculties that produce Kant's maxim. It seems that many moral beliefs in which humans are regarded as means to ends will also lead to less killing and more survival.

Although positing survival as a Milvian Bridge between evolutionary success and moral BFFs does not help fine-grained moral beliefs, it shows that natural selection can select for true, coarse-grained metaphysical beliefs.

I argued that sanctification can serve as a Milvian Bridge between religious beliefs and evolutionary success. Many religious traditions hold that engaging with God leads to a positive transformation that benefits well-being. Human well-being very probably also benefits human survival. ${ }^{27}$ As Bennett rightly notes, putative metaphysical truths like 'Jesus was the Son of God or 'Allah spoke to Muhammad' do not exert much causal influence within the spatio-temporal realm. Some religious beliefs are even downright non-adaptive. For a long period of history, accepting Christian beliefs put one in danger of persecution. The same also holds for other religious beliefs, such as those that were deemed heretical. Some religious beliefs also incline people to act non-adaptively. Indic beliefs about self-deprivation or other ascetic beliefs often worsen people's health. ${ }^{28}$ The 
benefits of believing such truths are enjoyed in the afterlife, the next life, or not at all. I argue that more coarse-grained putative metaphysical truths such as 'God exists' or 'God is loving' do have sufficient causal influence. If there is a God, engaging with Him probably affects how people live their lives. This effect can lead to greater sanctity and increased flourishing. If there is a loving God, engaging with God will have similar effects as engaging with loving human subjects. Much research strongly suggests that supportive social relationships are associated with lower levels of stress. ${ }^{29}$

Bennett's claim that multiple, conflicting fine-grained religious beliefs can make a claim to pragmatic value is compatible with what I've claimed so far. In their original defence of pragmatic value for physical beliefs, W\&G note that different conceptual frameworks can yield the same (or similar) pragmatic value. They note that some animals are able to pick up more or different sensory inputs. The input probably makes some animals have different conceptual schemes from those which the common-sense scheme humans have. ${ }^{30} \mathrm{~W} \& \mathrm{G}$ argue that a plurality of conceptual frameworks that yield comparable pragmatic success need not be a problem because all appear to be constrained by reality. They write:

\footnotetext{
But there is no reason to abandon the world of commonsense, as long as we are prepared to accept that we are not the only animal whose evolved perceptual and conceptual schemes can stand alongside the measurement and conceptual schemes of science, and be explained by it. There really are red things and green things, but there are also things which have ultra-violet colours that we cannot detect but other animals can. There are many ways of classifying the world which are not purely arbitrary and it is the fact that these classifications are constrained by reality that explains why they have some degree of pragmatic utility. (Wilkins \& Griffiths (2013), 140)
}

If we apply this argument to religious beliefs, different religious schemata, such as Christianity or Islam, can be regarded as constrained by the same reality to some extent, insofar as there is a God with whom people can engage. For people with a Christian conceptual schema, that reality will be regarded as the Trinitarian God. Muslims will regard that reality as the Muslim God. Which is more approximately true cannot be decided by the pragmatic value alone.

A denier of my claim that coarse-grained religious beliefs can have pragmatic value could argue that the effects on sanctity and human flourishing are due to natural factors, not contact with God. For example, one could argue that religious believers enjoy beneficial effects from religious beliefs, but these effects should be attributed to social relationships or stronger family ties. Religious believers in the west regularly attend religious services. Religious services are (among other things) occasions for social contact. We noted that supportive social relationships lead to lower stress. Christian churches also attach great importance to the family. Attending Christian churches could lead to stronger family ties and human flourishing. An opponent could argue that the beneficial effects of religious beliefs are entirely due to these, natural factors.

Against this response, I argue that the conclusion has insufficient empirical support. Reducing the pragmatic value of religious beliefs to the effects of solely 
natural factors requires more scientific and experimental evidence than is currently available.

\section{Coarse-grained beliefs are not the saviour of religion}

In this section I give my riposte to Van Eyghen's parrying of my attack on metaphysical beliefs. He argues that for both moral and religious beliefs, it is adaptive for humans to have approximately correct beliefs in some, broad areas. I disagree. I believe that major, inevitable assumptions must be made in order to sustain such a defence. Once one makes such assumptions, one largely defeats the purpose of any defence of the pragmatic success of metaphysical beliefs. Moreover, Van Eyghen's coarse-grained beliefs do not suffice to salvage religion even if admitted. Hence, his proposal is not ultimately successful, despite its originality.

Van Eyghen presents a fascinating case against my assertion that the truth value of metaphysical beliefs is not adaptive. He is right to defend the adaptive value of correct religious and moral beliefs, as that would be the simplest way to evade debunking arguments against such beliefs. Van Eyghen's view corresponds with mine on the value of the Milvian Bridge as an epistemic principle and test of reliable faculties. We also agree that by and large, perceptual BFFs (as well as inferential BFFs and others whose truths concern the physical world) are constrained by physical reality such that it is beneficial to be able to track truths of that kind, so that they cross the Milvian Bridge.

Our opinions diverge on which other faculties cross the Milvian Bridge. Van Eyghen believes, by using David Enoch's work on moral realism, he can bring metaphysical faculties across the Bridge and secure their reliability. He characterizes my objection to such a move well - while there are plentiful ways in which physical truths may influence upon organisms, it is much harder to imagine that, within traditional theological/moral frameworks, metaphysical truths exert an adaptive influence. Van Eyghen introduces Enoch's argument, which is that a 'third-factor response' (an external means of validating truths) allows moral realists to argue that certain true beliefs would be evolutionarily advantageous despite no apparent physical effects.

Unobjectionably, Enoch posits that beliefs such as 'killing is wrong' cause evolutionary advantage, particularly by enhancing a community's safety. He also argues that survival is a moral good. Therefore, there are certain moral beliefs that appear to be adaptive by virtue of the fact that they cause morally good behaviours (such as not killing, which aids survival). Hence, there is a supposed connection between tracking moral truths accurately and evolutionary benefit. This connection translates to religious beliefs, Van Eyghen postulates. He admits that 'fine-grained' beliefs such as 'Jesus was the Son of God' do not bring benefit but argues that 'coarse-grained' truths such as 'A loving God exists' are adaptive. He also asserts that these 'coarse-grained' beliefs increase fitness because they are 
true. This is an all-important step in proposing a third-factor response to help religious beliefs across the Milvian Bridge; without this the connection between fitness and truth is not solidified. Thus, Van Eyghen claims to have found a tenable link between pragmatic success and the generation of true religious beliefs.

\section{Assuming the position}

The distinction between 'coarse-grained' and 'fine-grained' beliefs applies usefully to many domains. For example, if one were to apply it to visual BFFs, it is evolutionarily beneficial for us to have 'coarse-grained' beliefs: we can distinguish a dangerous spiky-shaped berry from a delicious smoothly shaped one. However, it is not beneficial for us to have as fine-grained vision faculties as an eagle, which is able to notice a rabbit moving through grass two miles away. That is because for an eagle being able to do so provides evolutionary benefit, whereas such fine-tuned faculties would be wasted on humans. This spectrum between coarse-grained and fine-grained beliefs for perceptual faculties demonstrates the distinction to be a meaningful one. I also agree with Van Eyghen that finegrained metaphysical beliefs are too specific to link with pragmatic success, so a focus on the coarse-grained is legitimate.

However, that is as far as my agreements go. Enoch's version of the argument, as can be seen from my summary of it, makes a critical assumption without which it would be powerless. That is, Enoch states that survival is a moral good. On what grounds does he claim this? Primarily the grounds that evolution enforces a striving for survival on each organism, making it the human telos as well. This means that humans, like any other organisms, ought to aim for it. He claims that one only needs to assume that survival is 'at least somewhat good', lessening the burden on this assumption. But it still underpins his argument (Enoch (2010), 18). The problem with this reasoning is that it utilizes BFFs that do not cross the Milvian Bridge. BFFs that would generate moral beliefs (such as 'survival is good') cannot trace their fitness production back to their truth-tracking ability.

This is a serious problem for Enoch because it leaves him vulnerable to accusations of begging the question. He builds towards his conclusion that moral beliefs can be justified by providing a moral judgement: that survival is a moral good. So, for Enoch to posit an argument in defence of the reliability of moral beliefs, he has to assume the reliability of moral beliefs (or, more accurately, one specific moral belief). It matters not how coarse- or fine-grained are the beliefs Enoch defends, because he maintains an incoherent set of propositions. This is evidently a circular argument; hence I disagree that it constitutes a tenable link between pragmatic success and moral beliefs.

Van Eyghen justifies his view that coarse-grained religious beliefs must be true in order to be adaptive by positing that if there is a loving God with whom to relate, then believing in that God and acting appropriately would be beneficial, just as 
social relationships assist human flourishing. His argument would supply thirdfactor justification of the reliability of religious BFFs. But it suffers the same issue as Enoch's. The comparable assumption made by Van Eyghen is that human survival or flourishing is a religious good. If one permits this assumption, then it is indeed reasonable that, if there were a God, He would promote such a thing. But without initially assuming humanity's ability to know religious truths, how can we know that God wishes to promote human survival and flourishing? His argument problematically begs the question in the same way Enoch's does, because it connects pragmatic success and true religious beliefs by assuming the truth of a particular religious belief.

Both Van Eyghen and Enoch make further assumptions when marshalling arguments in support of their views. Enoch, besides assuming that survival is a moral good, assumes objective moral goods exist. This has a direct parallel in Van Eyghen's interpretation, wherein he assumes that God exists. The prior assumptions that I revealed were more specific, concerning an obvious fact that each takes as given. These were similar to the facts that they aimed to prove, so assuming them made the argument question-begging. The less explicit assumptions concern general metaphysics. These are the broader questions that Van Eyghen and Enoch aim to solve, so assuming those answers destabilizes their entire enterprises. What value is there in linking pragmatic success with religious beliefs, if one assumes that religious beliefs are true in any case? If the only way to link pragmatic success with religious beliefs is to assume the existence of God, then the whole project is devalued. There is no need to dispute the pragmatic success of true religious beliefs if one is comfortable with assuming one's beliefs are true from the outset.

Erik Wielenberg defends Enoch's use of third-factor responses from allegations of question-begging (Wielenberg (2016), 4-5). He lowers the burden on such responses by claiming that they need not provide fresh justification, but can instead deflect a potential defeater for justification by showing that EDAs do not undercut the targeted beliefs. Such a response does not save Van Eyghen's argument, because the undercutting power of W\&G's EDA stems from the plausible fact that religious BFFs' success is uncorrelated with the truths they provide. To claim that religious beliefs arose due to their accuracy in mapping the spiritual environment is a contrary claim, which must be evidenced properly. One cannot lower expectations by stating that an assumed counter deflects the EDA without the need for evidence. However reasonable it might seem to claim that survival is an a priori good, it remains an assumption that must stand on its own terms, and it cannot form the basis of an effective link between pragmatic success and religious belief without an (as yet unprovided) effective argument why it can be safely assumed. Wielenberg's defence from question-begging is unconvincing, and Van Eyghen's assumptions thus remain impermissibly bold. 


\section{What do coarse beliefs do?}

It might be argued that by dismissing Van Eyghen's and Enoch's assumptions I have been too inflexible. Of course, assumptions are required for many domains of knowledge to function. There may be real advantages to Van Eyghen's distinction between coarse-grained and fine-grained beliefs. Therefore, I wish to look specifically at that response, allowing his assumptions. If indeed it is evolutionarily beneficial, for whatever reason, to have correct coarse-grained religious beliefs, does this do the work that Van Eyghen requires?

As examples of coarse-grained religious beliefs, Van Eyghen offers 'God exists' and 'God is loving'. Statements such as 'Jesus was the Son of God' or 'Allah spoke to Muhammad' would constitute more fine-grained beliefs. These latter beliefs are at least as essential, if not even more so, to the doctrines of their respective religions as the former. Van Eyghen only claims that it is adaptive to believe the coarse-grained beliefs, because they might make one more loving or pro-social, and thus fitter. The Milvian Bridge principle would thus have no purchase on coarse-grained religious beliefs. Restating the purpose and basic function of Van Eyghen's argument highlights its insufficient ambition. Even if it succeeds on its own terms, it does not achieve its ultimate aspiration, the defence of fine-grained religious beliefs.

Another problem is that there is some evidence to suggest that people don't act on their coarse-grained religious or ethical beliefs. Studies delving into the widespread phenomenon of theological incorrectness show that despite people having certain beliefs about God and what they ought to do in response to such beliefs, they quite commonly act in ways that do not accord with those beliefs. ${ }^{31}$ Given that it is actions, not beliefs, to which natural selection is sensitive, this would be a serious problem for Van Eyghen. However, I will allow for now that people who believe God exists and is loving will act accordingly.

Apart from less significant worries, there is a more substantial issue. Evidently, by using a third-factor response Van Eyghen aims to bring religious BFFs across the Milvian Bridge. But bringing over certain coarse-grained beliefs, and faculties that generate such beliefs, is not the same as demonstrating the truth-tracking nature of religious BFFs. How would one construct a religion, an entire system of beliefs and practices, with only coarse-grained beliefs? It seems impossible. A believer who merely held the correct belief that there is a loving God could not really participate in a religion on the basis of just that. Fine-grained beliefs form the depth and breadth of the religion. What relationship does God have with humans? How does God act in the world? What is God's will? All these questions lack an answer that would be fitness-enhancing only if it were true. I thus find it incredible that Van Eyghen's argument has brought 'religion' in any important way over the Milvian Bridge.

The presumed objection to my point would be that once one shows certain religious beliefs are likely to be truth-tracking, others will follow. For example, if it is beneficial to know that God is loving, one can deduce that humans ought to be 
loving, and then act in that way. Equally, it might be possible to assume that God, being loving, will protect me, so I expand my group, producing further fitness. I find this approach unfeasible. I agree that, given the assumptions made, certain coarse-grained beliefs could be beneficial to know only if true. However, the notion that these coarse-grained beliefs are sufficient for the task that Van Eyghen sets them relies on further assumptions about what humans do, given the knowledge they have. A human who knows that God is loving can act upon that knowledge in various ways, many of which will not accord with the theistic beliefs that Van Eyghen hopes to defend. For example, a man might think that God loves all humans and so wants them to be with Him in heaven, and thus kills himself. There is no coarse-grained belief contradicting that action, so it is entirely possible. Therefore, coarse-grained religious beliefs are inappropriate as a foundation for theism.

To conclude, having assessed the arguments in favour of the pragmatic value of true religious beliefs, I find them unconvincing. The counters to a W\&G-style attack against religious BFFs fail to show that religious beliefs would be pragmatically useful only if true, leaving beliefs of that nature vulnerable. I hope to have exhibited that if one accepts the Milvian Bridge epistemic criterion, religious beliefs are jeopardized, because there is no indication whatsoever that the pragmatic success of religious beliefs is linked to their objective truth. ${ }^{32}$

\section{References}

Alston, William P. (1991) Perceiving God: The Epistemology of Religious Experience (Ithaca NY: Cornell University Press).

BeiLBy, J. K. (2002) Naturalism Defeated? Essays on Plantinga's Evolutionary Argument against Naturalism (Ithaca NY: Cornell University Press).

Bering, Jesse (2002). 'The existential theory of mind', Review of General Psychology, 6, 3-24.

Boudry, MaArten, \& Vlerick, Michael (2014) 'Natural selection does care about truth', International Studies in the Philosophy of Science, 28, 65-77.

BRADDOCK, Matthew (2016) 'Debunking arguments and the cognitive science of religion', Theology and Science, 14, 268-287.

Campbell, W. Keith, \& Sedikides, Constantine (1999) 'Self-threat magnifies the self-serving-bias: a meta-analytic integration', Review of General Psychology, 3, 23-43.

Carlson, Vicki, Cicchetti, Dante, Barnett, Douglas, \& Braunwald, Karen (1989) 'Disorganized/disoriented attachment relationships in maltreated infants', Developmental Psychology, 25, 525-531.

ChiAng, TED (2001) Hell is the Absence of God (New York: Tor Books).

Cowan, Ross (2016) Constantine's Battle for Empire and Faith (Oxford: Osprey).

Darwin, Charles (1881) 'Letter to William Graham, Down, July 3rd, 1881', in Francis Darwin (ed.) The Life and Letters of Charles Darwin Including an Autobiographical Chapter, I (London: John Murray, 1887), 315-317.

ENOCH, DAVID (2010). 'The epistemological challenge to metanormative realism: how best to understand it, and how to cope with it', Philosophical Studies, 148, 413-438.

Farias, Miguel, \& Newheiser, Anna-Kaisa (2019) 'The effects of belief in God and science on acute stress', Psychology of Consciousness: Theory, Research, and Practice.

Goodnick, Liz (2016). 'A de jure criticism of theism', Open Theology, 23-33.

Gould, Stephen JAY, \& Lewontin, Richard C. (1979) 'The spandrels of San Marco and the Panglossian paradigm: a critique of the adaptationist programme', Proceedings of the Royal Society of London B: Biological Sciences, 205(1161), 581-598. 
Johnson, Dominic P. (2015) God Is Watching You: How the Fear of God Makes Us Human (New York: Oxford University Press).

Jong, Jonathan, \& Visala, AKU (2014) 'Evolutionary debunking arguments against theism, reconsidered', International Journal for Philosophy of Religion, 76, 243-258.

JoyCE, Richard (2007a) The Evolution of Morality (Cambridge MA: MIT Press).

JoYCE, RichARD (2007b) The Myth of Morality (Cambridge MA: Bradford Books).

KaHANE, Guy (2011) 'Evolutionary debunking arguments', Noûs, 45, 103-125.

Kant, Immanuel (1993) Grounding for the Metaphysics of Morals: With On a Supposed Right to Lie Because of Philanthropic Concerns (Cambridge MA: Hackett).

KyriaCou, C (2019) 'Evolutionary debunking: the Milvian Bridge destabilized', Synthese, 196, 2695-2713.

LEECH, D. \& VISALA, A. (2012) 'How relevant is the cognitive science of religion to philosophy of religion?', in Yujin Nagasawa (ed.) Scientific Approaches to the Philosophy of Religion (London: Palgrave Macmillan), 165-183.

Mann, Sebastian (2019) ' “God wanted Trump to be president” says Sarah Huckabee Sanders', The Times, 31 January.

McCauley, Robert N. (2007) 'Reduction: models of cross-scientific relations and their implications for the psychology-neuroscience interface', in Paul Thagard (ed.) Philosophy of Psychology and Cognitive Science (Amsterdam: Elsevier), 105-158.

Niniluoto, ILKKa (1987). Truthlikeness. Synthese Library. Springer Netherlands. //www.springer.com/us/book/ 9789027723543.

NolA, Rовевт (2013) ‘Do naturalistic explanations of religious beliefs debunk religion?', in Gregory W. Dawes \& James Maclaurin (eds) A New Science of Religion (New York \& London: Routledge), 162-188.

Nola, Roвert (2018) 'Demystifying religious belief', in Hans Van Eyghen, Rik Peels, \& Gijsbert van den Brink (eds) New Developments in the Cognitive Science of Religion (Cham: Springer), 71-92.

Oddie, Graham (2016) 'Truthlikeness', in Edward N. Zalta (ed.) The Stanford Encyclopedia of Philosophy, https://plato.stanford.edu/archives/win2016/entries/truthlikeness/.

Plantinga, Alvin (1993) Warrant and Proper Function (New York: Oxford University Press).

Plantinga, Alvin (2011) Where the Conflict Really Lies: Science, Religion, and Naturalism (Oxford: Oxford University Press).

Radvansky, G. A., \& Zacks, J. M. (2014) Event Cognition (Oxford: Oxford University Press).

SLONE, D. JASON (2004) Theological Incorrectness: Why Religious People Believe What They Shouldn't (Oxford: Oxford University Press).

Street, Sharon (2006) 'A Darwinian dilemma for realist theories of value', Philosophical Studies, 127, 109-166.

SZOCIK, KONRAD (2017) 'Religion and religious beliefs as evolutionary adaptations', Zygon, 52, 24-52.

Thurow, Joshua C. (2016) 'Some reflections on cognitive science, doubt, and religious belief', in Roger Trigg \& Justin L. Barrett (eds) The Roots of Religion (Abingdon: Routledge), 189-207.

Umberson, Debra, Chen, Meichu D., House, James S., Hopkins, Kristine \& Slaten, Ellen (1996) 'The effect of social relationships on psychological well-being: are men and women really so different?', American Sociological Review, 61, 837-857.

VAn Eyghen, H. (2020). Arguing from Cognitive Science of Religion: Is Religious Belief Debunked? (London: Bloomsbury Academic).

Wielenberg, ERIK J. (2016) 'Ethics and evolutionary theory', Analysis, 76, 502-515.

Wilkins, John S., \& Griffiths, PAul E. (2013) 'Evolutionary debunking arguments in three domains: fact, value, and religion', in Gregory Dawes \& James Maclaurin (eds) A New Science of Religion (Abingdon: Routledge), 133-146.

\section{Notes}

1. Darwin wrote:

the horrid doubt always arises whether the convictions of man's mind, which has been developed from the mind of the lower animals, are of any value or at all trustworthy. Would any one trust in the convictions of a monkey's mind, if there are any convictions in such a mind? (Darwin (1881), 316)

2. For the argument and replies, see Beilby (2002), Boudry \& Vlerick (2014). 
3. What 'fitness of an organism' means is somewhat ambiguous. The term can refer to the fitness of the individual organism, the type of organism in a population, and the individual's inclusive or average fitness. In the remainder of this article, we will use the term 'fitness of the individual' as meaning the inclusive fitness of an individual organism.

4. A recent example is the argument by Joyce (2007b).

5. Plantinga's $(1993 ; 2011)$ evolutionary argument against naturalism is sometimes read as a debunking argument against common-sense and scientific beliefs.

6. See for example Campbell \& Sedikides (1999).

7. Liz Goodnick (2016) makes a similar claim. The debate originated in the field of moral realism with Sharon Street's (2006) postulate of the 'Darwinian Dilemma'.

8. See Johnson (2015).

9. See Gould \& Lewontin (1979).

10. See Bering (2002).

11. See Szocik (2017).

12. Wilkins and Griffiths take the term 'Milvian Bridge' from Constantine's famous battle of AD 312. For an explanation of the term, see Wilkins \& Griffiths (2013), 125. For more information on the battle of Milvian Bridge, see Cowan (2016), 14.

13. For example, they write: '[O]ur cognitive faculties evolved because they track truth in the human 'Umwelt" (Wilkins \& Griffiths (2013), 131).

14. W\&G refer to the self-serving bias (see above).

15. This is argued in similar ways by Thurow (2016) and Jong \& Visala (2014). For a more thorough discussion of this reply to debunking arguments see Van Eyghen (2020), sect. 5.3.

16. For example, Niiniluoto (1987); Oddie (2016).

17. Successful interaction with God requires more than having approximately true religious beliefs. It also requires a response from God and knowing what the right means are for interacting with God.

Nonetheless, subjects with approximately true religious beliefs are more likely to interact successfully with God than subjects with false religious beliefs.

18. Intuitively, sanctity is correlated to reduced stress and better health. There is, however, some evidence that religious reflection and meditation do not help individuals cope with stress (Farias \& Newheiser (2019) ). Achieving sanctity, however, requires more than religious reflection or meditation.

19. Some studies found that maltreatment in infancy led to disorganized or disoriented attachment relations with caregivers or partners (Carlson et al. (1989)). Lack of flourishing due to maltreatment could be a mediator between maltreatment and disorganized/disoriented attachment.

20. See Radvansky \& Zacks (2014).

21. Debate over the effectiveness of an EDA such as W\&G's extends beyond this article's scope. For a sample critique of its self-coherence, see Kyriacou (2019). Meanwhile, Thurow (2016) argues, supported by Leech \& Visala (2012, 8-10), that even if a Faculties EDA succeeds, it does not affect many religious beliefs, because beliefs can still be justified by natural theology. Although there is insufficient space to address these critiques properly here, I note that W\&G themselves address incoherence when ensuring that common-sense beliefs can be justified, as discussed earlier. Moreover, there will be at least some religious beliefs threatened by this EDA; especially those based on processes described by CSR or those not secured by natural theology.

22. This is an oversimplification of natural selection, which is really based on relative rates of reproduction, but it displays the central point, that accurate empirical faculties are fitness-enhancing.

23. See Cowan (2016). For a topical example of this phenomenon, see Sarah Huckabee Sanders's recent comments on Donald Trump, explaining that the reason he won was because he had God on his side! (Mann (2019)).

24. As pointed out by a reviewer, one can imagine an environment in which religious truth-tracking is beneficial. For an example of such an environment, see Ted Chiang's (2001) story 'Hell is the absence of god'.

25. See for example Joyce (2007a).

26. In this regard, third factor analyses are an objection to W\&G's claim that moral beliefs have no Milvian Bridge available.

27. This last point is not obviously true. People who constantly worry might answer evolutionary challenges effectively. They could ensure they have sufficient resources for survival, avoiding dangers. There is, however, evidence that increased stress causes illnesses and discomfort. 
28. I thank an anonymous reviewer for suggesting these examples of non-adaptive religious beliefs.

29. See Umberson et al. (1996).

30. Many if not most animals probably do not have conceptual schemes. There is some evidence that some apes and dolphins do.

31. See Slone (2004).

32. We thank John Wilkins and two anonymous referees for helpful comments on earlier drafts. 